\title{
Alfaxalone anaesthesia in the green iguana (Iguana iguana)
}

\author{
Zdeněk Knotek ${ }^{1,2}$, Anna Hrdá1, Zora Knotková ${ }^{1}$, Šárka Trnková1, Vladimír Babák ${ }^{3}$ \\ ${ }^{1}$ University of Veterinary and Pharmaceutical Sciences Brno, Faculty of Veterinary Medicine, Avian and Exotic \\ Animal Clinic, Brno, Czech Republic \\ ${ }^{2}$ University of Veterinary Medicine, Clinic for Avian, Reptile and Fish Medicine, Vienna, Austria \\ ${ }^{3}$ Veterinary Research Institute, Brno, Czech Republic
}

Received December 9, 2011

Accepted November 29, 2012

\begin{abstract}
The aim of this study was to evaluate short-term intravenous anaesthesia with alfaxalone in green iguanas (Iguana iguana). Alfaxalone at a dose rate of $5 \mathrm{mg} / \mathrm{kg}$ was administered to thirteen adult male green iguanas via the ventral caudal vein following $24 \mathrm{~h}$ fasting. The induction time, tracheal tube insertion time, surgical plane of anaesthesia interval, and full recovery time were recorded. Systolic, diastolic and mean arterial blood pressure (measured indirectly), pulse rate, respiratory rate, $\mathrm{SpO}_{2}$ and $\mathrm{ETCO}_{2}$ were recorded. The induction time and tracheal tube insertion time was $41.54 \pm 27.69 \mathrm{~s}$ and $69.62 \pm 37.03 \mathrm{~s}$, respectively. The time from the alfaxalone administration to the loss of toe-pinch reflex was $2.20 \pm 1.47 \mathrm{~min}$. Full activity was restored $14.23 \pm 4.15 \mathrm{~min}$ after the initial alfaxalone administration. The respiratory rate increased significantly $(P<0.01)$ from $4.3 . \pm 3.2$ to $6.8 \pm 1.6$ breaths per min and a gradual decrease of ETCO from $43.65 \pm 10.54$ to $26.58 \pm 8.10 \mathrm{mmHg}(P<0.01)$ was noted from the second to the $13^{\text {th }} \mathrm{min}$ after alfaxalone administration. The pulse rate, $\mathrm{SpO}_{2}$ and blood pressure did not change significantly. Intravenous use of alfaxalone proved to be a suitable and safe form for short term anaesthesia in green iguanas.
\end{abstract}

Reptiles, reflexes, monitoring capnography, respiration

Alfaxalone (3- $\alpha$-hydroxy-5- $\alpha$-pregnane-11,20-dione) represents a veterinary alternative of drugs used for controlled sedation or anaesthesia (Leece et al. 2009). The benefits of alfaxalone in small animals include rapid induction and fast recovery (Maddern et al. 2010). Injection of alfaxalone is not painful and no irritation or inflammation was observed even after perivascular administration. To date, alfaxalone has been tested mainly in mammals (Ferre et al. 2006; Muir et al. 2008, 2009; Leece et al. 2009; Maddern et al. 2010) where the administration of high doses can be associated with certain complications (Muir et al. 2009; Maddern et al. 2010). Adverse effects of alfaxalone include temporary hypotension, and higher doses may result in prolonged apnea (Leece et al. 2009; Muir et al. 2009; Maddern et al. 2010). Only a few clinical studies on the use of alfaxalone in reptiles have been published (Carmel 2002; Simpson 2004; Scheelings et al. 2010). These studies vary both in the amount of recommended dose and the description of clinical signs observed in reptiles. The assessment of alfaxalone as a short-acting anaesthetic agent or as an induction agent prior to inhalation anaesthesia is timely (Maddern et al. 2010). Previously, in reptiles, propofol was used for these purposes (Bennett 1996; Heard 2001).

The aim of this study was to evaluate short-term intravenous anaesthesia with alfaxalone in healthy green iguanas (Iguana iguana) kept experimentally.

\section{Materials and Methods}

The clinical research was performed with a group of 13 adult male green iguanas (Iguana iguana) aged 6 to 10 years, with an average weight of $1.31 \pm 0.67 \mathrm{~kg}$, housed at the Avian and Exotic Animal Clinic of the University of Veterinary and Pharmaceutical Sciences, Brno, Czech Republic. The animals were housed and handled with the

Address for correspondence:

Prof. MVDr. Zdeněk Knotek, CSc. Dipl ECZM (herpetology).

Avian and Exotic Animal Clinic, Faculty of Veterinary Medicine

University of Veterinary and Pharmaceutical Sciences

Brno, Czech Republic

Phone: +420604205305

Fax: + 420541562381

E-mail: knotekz@vfu.cz

http://actavet.vfu.cz/ 
agreement of the Branch Commission for Animal Welfare of the Ministry of Agriculture of the Czech Republic (accreditation No. 46613/2003-1020). The iguanas were housed in terrariums with a $12 \mathrm{~h} / 12 \mathrm{~h}$ day/night cycle provided by $100 \mathrm{~W}$ incandescent bulbs and ultraviolet light lamps (Repti-Glo 5.0/T8, $60 \mathrm{~cm}, 20 \mathrm{~W}$ UV-B; Hagen, Germany). Temperature in the terrariums ranged from 24 to $35^{\circ} \mathrm{C}$ and air humidity from 60 to $80 \%$. The iguanas had unrestricted access to water which they used for drinking, bathing and as a latrine. They were fed a daily diet of common dandelion leaves, Chinese cabbage, carrots, cucumbers and apples. Their health was evaluated by repeated clinical examinations and by evaluating blood profiles including full haematology and plasma chemistry. After fasting for $24 \mathrm{~h}$ the iguanas were anaesthetised using alfaxalone (Alfaxan ${ }^{\circledR} 10 \mathrm{mg} / \mathrm{ml}$; Vétoquinol, France) as a bolus dose of $5 \mathrm{mg} / \mathrm{kg}$ via the ventral caudal vein (vena cocccygea ventralis). The iguanas were placed on an electric heating pad (Bosch PFP 1031; Bosch, Czech Republic) kept at $37.5^{\circ} \mathrm{C}$. Selected clinical indicators were continuously recorded including the loss of righting reflex, loss of glottal control enabling the insertion of the endotracheal tube (Bicakcilar, Istanbul, Turkey), loss of toe-pinch reflex on the pelvic limb, the restoration of toepinch reflex, restoration of the righting reflex and voluntary movement. The time from the injection of alfaxalone to the loss of the righting reflex was recorded as induction time. The time from the injection of alfaxalone to the loss of glottal control was recorded as tracheal tube insertion time. The time from the injection of alfaxalone to the loss of the toe-pinch-reflex was recorded as deep pain sensation loss. The time from the loss of the toe-pinch reflex to the restoration of the toe-pinch reflex was recorded as surgical plane of anaesthesia interval.

The time from the administration of alfaxalone to the restoration of the righting reflex and voluntary movement was recorded as the time of full recovery (Bennett 1991, 1996). Systolic arterial blood pressure (SAP), diastolic arterial blood pressure (DAP) and mean arterial blood pressure (MAP), pulse rate, respiratory rate, oxygen saturation of haemoglobin $\left(\mathrm{SpO}_{2}\right)$ and end-tidal carbon dioxide concentration $\left(\mathrm{ETCO}_{2}\right)$ were measured (BASi/VETRONICS VitalScan monitor; Vetronic, UK). The pulse oxymeter probe (veterinary transreflectance sensor) monitoring $\mathrm{SpO}_{2}$ and pulse rate was inserted in the oesophagus. The ETCO, probe (mainstream) and the respiratory rate probe were both connected to the connector of the tracheal tube. Blood pressure was measured indirectly using a cuff placed around the proximal left pelvic limb. Individual values were recorded every minute, except for blood pressure indicators that were monitored and recorded every $3^{\text {rd }} \mathrm{min}$.

Average values, arithmetic mean and sample standard deviation (s), were calculated using Microsoft Office Excel 2007 application (Microsoft Corp., Redmond, WA, USA). Statistical analysis of measured indicators was performed by the statistical software GraphPad Prism 5.04 (GraphPad Software, Inc., San Diego, CA, USA). Changes in blood pressure (SAP, DAP, MAP) during the monitored interval were analysed by the one-way ANOVA (significance of differences was tested by the F-test); other indicators (pulse rate, respiratory rate, $\mathrm{SpO}_{2}$ and $\mathrm{ETCO}_{2}$ ) were analysed by the methods of linear regression (fit of the model was confirmed by the F-test, significance of the estimated model indicators was checked by $t$-test, $P<0.01$ ).

\section{Results}

The results of the anaesthesia are presented in Tables 1-6. After the intravenous administration of alfaxalone the righting reflex was usually lost within $1 \mathrm{~min}(41.54 \pm 27.69 \mathrm{~s})$. An endotracheal tube could be inserted within $2 \mathrm{~min}(69.62 \pm 37.03 \mathrm{~s})$. A surgical plane of anaesthesia was repeatedly achieved between 2 and $9 \mathrm{~min}$; full activity was restored within $20 \mathrm{~min}$ after the initial injection of alfaxalone $(14.23 \pm 4.15 \mathrm{~min}$, Table 1). Blood pressure values (Table 2), pulse rate (Table 3), respiratory rate (Table 4), $\mathrm{SpO}_{2}$ (Table 5) and $\mathrm{ETCO}_{2}$ (Table 6) could be read only after the iguanas were anaesthetised and probes were connected. Therefore tables contain data obtained from the $2^{\text {nd }}$ or $4^{\text {th }}$ min of measurement. As the lizards started to recover, the number of animals whose indicators could be measured decreased, consequently the tables only demonstrate data obtained within the first $13 \mathrm{~min}$. The pulse rate, $\mathrm{SpO}_{2}$ and blood pressure (SAP, DAP, MAP) did not change significantly (F-test: $P>0.05)$ during this monitored interval. The respiratory rate increased significantly (F-test: $P<0.01$, $t$-test: $P<0.01$ for both model indicators) from $4.3 . \pm 3.2$ to $6.8 \pm 1.6$ breaths per min and a gradual decrease of $\mathrm{ETCO}_{2}$ from $43.65 \pm 10.54$ to $26.58 \pm 8.10 \mathrm{mmHg}$ (F-test: $P<0.01$, $t$-test: $P<0.01$ for both model indicators) was noted from the $2^{\text {nd }}$ to the $13^{\text {th }}$ min after alfaxalone administration.

\section{Discussion}

In the few published studies conducted on the use of alfaxalone in reptiles there is considerable variation in recommended dose rates and degree of anaesthetic monitoring. However, several studies described a reliable induction of anaesthesia with the loss of deep 
Table 1. Alfaxalone anaesthesia (5 mg/kg i.v.) in 13 male green iguanas.

\begin{tabular}{lcccc}
\hline Time & Mean & s & Min & Max \\
\hline $\begin{array}{l}\text { Induction time (s) } \\
\text { Tracheal tube }\end{array}$ & 41.54 & 27.69 & 10 & 120 \\
$\begin{array}{l}\text { Insertion (s) } \\
\text { Toe-pinch }\end{array}$ & 69.62 & 37.03 & 30 & 180 \\
reflex loss (min) & & & & 6 \\
Toe-pinch & 2.20 & 1.47 & 1 & 15 \\
reflex restoration (min) & 8.60 & 2.18 & 6 & 21 \\
Full recovery (min) & 14.23 & 4.15 & 6 & \\
\hline
\end{tabular}

Table 2. Blood pressure in green iguanas under alfaxalone anaesthesia ( $5 \mathrm{mg} / \mathrm{kg}$ i.v.).

\begin{tabular}{|c|c|c|c|c|c|}
\hline \multirow{2}{*}{ Iguanas (n) } & \multirow{2}{*}{ Minute } & \multicolumn{4}{|c|}{ Systolic blood pressure (mm $\mathrm{Hg})$} \\
\hline & & Mean & $\mathrm{s}$ & Min & Max \\
\hline 6 & $4^{\text {th }}$ & 81.0 & 16.6 & 55 & 98 \\
\hline 10 & $7^{\text {th }}$ & 84.5 & 15.4 & 59 & 115 \\
\hline 10 & $10^{\text {th }}$ & 82.1 & 5.7 & 75 & 92 \\
\hline 9 & $13^{\text {th }}$ & 79.7 & 11.7 & 62 & 103 \\
\hline \multirow{2}{*}{ Iguanas (n) } & \multirow{2}{*}{ Minute } & \multicolumn{4}{|c|}{ Diastolic blood pressure ( $\mathrm{mm} \mathrm{Hg}$ ) } \\
\hline & & Mean & $\mathrm{s}$ & Min & Max \\
\hline 7 & 4 th & 47.6 & 18.7 & 28 & 78 \\
\hline 8 & 7 th & 50.0 & 15.0 & 30 & 77 \\
\hline 10 & 10 th & 58.4 & 17.0 & 34 & 82 \\
\hline 8 & 13 th & 51.8 & 9.3 & 41 & 65 \\
\hline \multirow{2}{*}{ Iguanas (n) } & \multirow{2}{*}{ Minute } & \multicolumn{4}{|c|}{ Mean blood pressure (mm Hg) } \\
\hline & & Mean & $\mathrm{s}$ & Min & Max \\
\hline 9 & 4th & 55.4 & 19.3 & 29 & 85 \\
\hline 9 & 7th & 67.7 & 10.5 & 50 & 82 \\
\hline 10 & 10th & 70.7 & 10.7 & 50 & 82 \\
\hline 9 & 13th & 63.4 & 6.8 & 51 & 72 \\
\hline
\end{tabular}

pain sensation within 2 min after intravenous administration of alfaxalone at the dose rate of $2-4 \mathrm{mg} / \mathrm{kg}$ and, subsequently, full restoration of activity 10 to $30 \mathrm{~min}$ later (Carmel 2002; Simpson 2004). In varanids (monitor lizards, Varanidae) and agamids (dragon lizards, Pogona sp.), alfaxalone was used at a dose rate of $5 \mathrm{mg} / \mathrm{kg}$ when the opioid analgesic butorphanol was administered $30 \mathrm{~min}$ before alfaxalone application. This combination was followed with a smooth recovery of reptiles. On the other hand, satisfactory anaesthesia was not achieved after administration of alfaxalone alone at a dose of $9 \mathrm{mg} / \mathrm{kg}$ in a study on Australian lizard species, although in most of them except for blotched bluetongue lizards (Tiliqua nigrolutea) an endotracheal tube could be inserted (Scheelings et al. 2010).

In our study performed on 13 healthy adult green iguanas, the loss of deep sensation persisted from $2.20 \pm 1.47$ to $8.60 \pm 2.18 \mathrm{~min}$ after alfaxalone administration, while full activity was restored $14.23 \pm 4.15 \mathrm{~min}$ after alfaxalone administration. An endotracheal tube could be inserted in all 13 lizards. Considering that injectable anaesthetic agents are usually used in reptiles at lower doses in order to facilitate endotracheal intubation and ensure safe and easy induction of inhalation anaesthesia (Knotek 2010) the use of alfaxalone can be recommended in green iguanas. Intravenous alfaxalone administered 
Table 3. Blood pulse in green iguanas under alfaxalone anaesthesia ( $5 \mathrm{mg} / \mathrm{kg}$ i.v.).

\begin{tabular}{rrrrrc}
\hline \multirow{2}{*}{ Iguanas (n) } & Minute & \multicolumn{3}{c}{ Pulse/minute } \\
\cline { 3 - 6 } & & Mean & s & Min & Max \\
\hline 9 & 2nd & 60.3 & 13.6 & 46 & 85 \\
11 & 3rd & 61.8 & 12.4 & 46 & 80 \\
13 & 4th & 62.7 & 12.6 & 46 & 88 \\
12 & 5th & 64.3 & 12.3 & 47 & 89 \\
13 & 6th & 65.0 & 11.8 & 47 & 89 \\
13 & 7th & 64.3 & 11.0 & 48 & 89 \\
12 & 8th & 62.5 & 8.8 & 48 & 76 \\
12 & 9 th & 62.2 & 8.5 & 49 & 78 \\
12 & 10 th & 63.6 & 8.8 & 49 & 78 \\
12 & 11 th & 64.2 & 8.9 & 50 & 80 \\
10 & 12th & 62.3 & 4.5 & 55 & 69 \\
8 & 13th & 62.8 & 5.4 & 53 & 69 \\
\hline
\end{tabular}

Table 4. Respiratory rate in green iguanas under alfaxalone anaesthesia ( $5 \mathrm{mg} / \mathrm{kg}$ i.v.).

\begin{tabular}{|c|c|c|c|c|c|}
\hline \multirow{2}{*}{ Iguanas (n) } & \multirow{2}{*}{ Minute } & \multicolumn{4}{|c|}{ Breaths/minute } \\
\hline & & Mean & $\mathrm{s}$ & Min & Max \\
\hline 9 & 2nd & 4.3 & 3.2 & 1 & 9 \\
\hline 12 & $3 \mathrm{rd}$ & 4.9 & 3.3 & 1 & 11 \\
\hline 13 & 4 th & 5.1 & 3.3 & 1 & 9 \\
\hline 13 & 5 th & 5.4 & 3.4 & 1 & 11 \\
\hline 13 & 6th & 5.2 & 2.9 & 1 & 11 \\
\hline 13 & 7 th & 5.8 & 3.2 & 2 & 13 \\
\hline 12 & 8 th & 5.5 & 2.6 & 2 & 10 \\
\hline 12 & 9th & 5.8 & 2.3 & 3 & 10 \\
\hline 12 & 10th & 6.4 & 2.1 & 3 & 11 \\
\hline 12 & 11 th & 6.8 & 2.3 & 4 & 12 \\
\hline 10 & 12 th & 6.1 & 1.5 & 4 & 8 \\
\hline 9 & 13th & 6.8 & 1.6 & 4 & 9 \\
\hline
\end{tabular}

Table 5. $\mathrm{SpO}_{2}$ in green iguanas under alfaxalone anaesthesia $(5 \mathrm{mg} / \mathrm{kg}$ i.v. $)$.

\begin{tabular}{|c|c|c|c|c|c|}
\hline \multirow{2}{*}{ Iguanas (n) } & \multirow{2}{*}{ Minute } & \multicolumn{4}{|c|}{$\mathrm{SpO}_{2}(\%)$} \\
\hline & & Mean & $\mathrm{s}$ & Min & Max \\
\hline 8 & 2nd & 73.9 & 8.4 & 57 & 86 \\
\hline 11 & $3 \mathrm{rd}$ & 79.1 & 9.7 & 60 & 95 \\
\hline 12 & 4 th & 80.2 & 7.5 & 71 & 92 \\
\hline 13 & 5 th & 76.8 & 8.4 & 64 & 89 \\
\hline 13 & 6 th & 73.7 & 12.8 & 52 & 94 \\
\hline 13 & 7 th & 75.2 & 12.9 & 51 & 95 \\
\hline 12 & 8 th & 73.3 & 14.2 & 54 & 92 \\
\hline 11 & 9th & 77.1 & 10.3 & 54 & 88 \\
\hline 11 & 10th & 79.4 & 14.2 & 53 & 100 \\
\hline 12 & 11 th & 76.8 & 13.5 & 53 & 95 \\
\hline 9 & 12 th & 77.7 & 15.3 & 54 & 96 \\
\hline 9 & 13th & 78.9 & 12.1 & 58 & 91 \\
\hline
\end{tabular}


Table 6. $\mathrm{ETCO}_{2}$ in green iguanas under alfaxalone anaesthesia $(5 \mathrm{mg} / \mathrm{kg}$ i.v.).

\begin{tabular}{lccccc}
\hline \multirow{2}{*}{ Iguanas (n) } & \multirow{2}{*}{ Minute } & \multicolumn{5}{c}{$\mathrm{ETCO}_{2}(\mathrm{mmHg})$} \\
\cline { 2 - 6 } & & Mean & s & Min & Max \\
\hline 9 & 2nd & 43.65 & 10.54 & 26.7 & 60.4 \\
12 & 3rd & 38.06 & 11.91 & 19.6 & 56.4 \\
13 & 4th & 36.94 & 11.31 & 19.0 & 55.5 \\
13 & 5th & 35.07 & 11.32 & 18.2 & 53.5 \\
13 & 6th & 35.06 & 10.85 & 18.9 & 52.1 \\
13 & 7th & 33.46 & 8.96 & 18.9 & 46.7 \\
12 & 8th & 32.45 & 8.93 & 18.0 & 45.6 \\
12 & 9 th & 30.41 & 8.05 & 16.4 & 43.9 \\
12 & 10th & 28.98 & 7.44 & 15.4 & 42.2 \\
12 & 11th & 27.60 & 6.03 & 17.8 & 38.1 \\
10 & 12th & 28.25 & 6.40 & 19.7 & 38.7 \\
9 & 13th & 26.58 & 8.10 & 15.6 & 38.6 \\
\hline
\end{tabular}

at a dose rate of $5 \mathrm{mg} / \mathrm{kg}$ in green iguanas does not induce significant apnoea or affect cardiorespiratory functions. Comparing the effects of alfaxalone with those of propofol in reptiles, some authors suggest that the advantage of alfaxalone is that it has less cardiovascular side effects and a wider safety margin (Simpson 2004). However, comparison of this kind was not the subject of the present study. Gradual increase of respiratory rate and corresponding decrease of $\mathrm{ETCO}_{2}$ were significant. Systolic arterial blood pressure, diastolic arterial blood pressure, mean arterial blood pressure, pulse rate and $\mathrm{SpO}_{2}$ changed without any specific pattern and significance. The absence of differences in $\mathrm{SpO}_{2}^{2}$ values should be due to technical complications of this method. $\mathrm{SpO}_{2}$ values measured by pulse oximetry in reptiles have to be evaluated with caution (Diethelm et al. 1996). Based on the quick onset of action of intravenous injection of alfaxalone in green iguanas and the subsequent gradual change in the respiratory rate and $\mathrm{ETCO}_{2}$, it can be assumed that temporary changes in cardiovascular or respiratory function occur within the first 2 min of alfaxalone administration. It would be interesting to record and characterise changes in this early stage of anaesthesia, but it was not possible to ensure such measurements with the equipment available. Alfaxalone administered at a dose of $5 \mathrm{mg} / \mathrm{kg}$ i.v. in adult healthy green iguanas enabled endotracheal intubation. It proved to be a safe and reliable form of short-term anaesthesia and induction anaesthesia.

\section{Acknowledgments}

The authors extend their thanks to Dr. Robert S.P. Johnson, BVSc, MACVSc, CertZooMed, South Penrith Veterinary Clinic, Penrith, New South Wales, Australia and Dr. William Lewis, BVSc CertZooMed MRCVS, The Wylie Veterinary Centre, Upminster, Essex, The United Kingdom, for their valuable comments and kind help with translation of the manuscript. This project received partial support from the Internal Grant Agency of the University of Veterinary and Pharmaceutical Sciences Brno (IGA Nr. 32/2010/FVL).

\section{References}

Bennett RA 1991: A review of anaesthesia and chemical restraint in reptiles. J Zoo Wildlife Med 22: 282-303

Bennett RA 1996: Anaesthesia. In: Mader DR (Ed.). Reptile Medicine and Surgery. WB Saunders, Philadelphia. pp. 241-247

Carmel B 2002: Use of Alfaxan-CD for intravenous anaesthesia in reptiles. In: Control and Therapy. Post Graduate Foundation in Veterinary Science, No: 4413

Diethelm G, Mader DR, Grosenbaugh DA, Muir W 1996: Evaluating pulse oximetry in the green iguana (Iguana iguana). Proc. ARAV, Kansas City, pp. 11-12 
Ferre PJ, Pasloske K, Whittem T, Ranasinghe MG, Li Q, Lefebvre HP 2006: Plasma pharmacokinetics of alfaxalone in dogs after an intravenous bolus of Alfaxan-CD RTU. Vet Anest Analg 33: 229-236

Heard DJ 2001: Reptile anaesthesia. In: Heard DJ (Ed.) Analgesia and Anaesthesia. Veterinary Clinics of North America: Exotic Animal Practice. WB Saunders, Philadelphia. pp. 83-117

Knotek Z 2010: A practical approach to anaesthesia and analgesia in reptiles. Proc. ARAV, Munich, pp. 61-71

Leece EA, Girard NM, Maddern K 2009: Alfaxalone in cyclodextrin for induction and maintenance of anaesthesia in pones undergoing field castration. Vet Anest Analg 36: 480-484

Maddern K, Adams VJ, Hill NAT, Leece EA 2010: Alfaxalone induction dose following administration of medetomidine and butorphanol in the dog. Vet Anest Analg 37: 7-13

Muir W, Lerche P, Wiese A, Nelson L, Pasloske K, Whittem T 2008: Cardiorespiratory and anesthetic effects of clinical and supraclinical doses of alfaxalone in dogs. Vet Anest Analg 35: 451-462

Muir W, Lerche P, Wiese A, Nelson L, Pasloske K, Whittem T 2009: The cardiorespiratory and anesthetic effects of clinical and supraclinical doses of alfaxalone in cats. Vet Anest Analg 36: 42-54

Scheelings TF, Holz P, Haynes L, Mason P, Hammersley G, Elton I, Conner P, Stan M, Baker R 2010: A preliminary study of the chemical restraint of selected squamate reptiles with alfaxalone. Proc. ARAV, South Padre Island, pp 114-115

Simpson M 2004: Anaesthesia of Reptiles. Proc. UEPS/AVA National Conference, pp. 119-126 